\title{
RECONSTRUÇÃO DE MAXILA ATRÓFICA UTILIZANDO ENXERTO ÓSSEO AUTÓGÊNO DE CRISTA ILÍACA - RELATO DE CASO CLÍNICO
}

José Mário Domingos FRAIZ; Nelson Luis Barbosa REBELLATO; Delson João da COSTA; Paulo Roberto MÜLLER; Ricardo Pasquini FILHO.

A reabilitação oral de pacientes com maxilas atróficas tem sido bastante discutida na literatura. Esse trabalho apresenta a técnica de reconstrução de maxila atrófica através de enxertia óssea utilizando osso removido da crista ilíaca. De acordo com LIM et al em 2004, uma quantidade mínima de tecido ósseo é necessária para a inserção e manutenção da estabilidade do implante, após a perda dos dentes o processo alveolar maxilar pode sofrer reabsorção tanto vertical quanto horizontal, podendo atingir um estágio de pneumatização do seio maxilar que em alguns casos contra-indica a instalação de implantes. A literatura sugere que quando há a pneumatização acentuada do seio maxilar e reabsorção de rebordo alveolar, a técnica de sinus Lift, introduzida primeiramente por TANTUM em 1970, e revisada por MISCH na década de 80, é indicada. Dentre as áreas doadoras extra-orais a crista óssea do ilíaco tem sido uma das opções de escolha, segundo HARBON et al, por apresentar baixo índice de complicações pós-operatórias, baixa morbidade e menor reabsorção pós-cirúrgica Esta técnica permite, após seis meses da cirurgia, a instalação de implantes osseointegrados e posterior reabilitação protética. O presente trabalho apresenta um caso clínico de enxertia ósseo de crista ilíaca em maxila atrófica e reabilitação com implantes. 